\title{
Livro didático, Educação e Relações Étnico-raciais: o estado da arte ${ }^{1}$
}

\section{Textbook, Ethnic-Racial Relations and Education: a review}

\author{
Tania Mara Pedroso Muller ${ }^{*}$
}

\begin{abstract}
RESUMO
Este artigo apresenta os resultados do estudo realizado sobre o "Estado da arte" da produção acadêmica brasileira a respeito do livro didático e relações étnico-raciais. Baseando-se nessa metodologia, a pesquisa teve como universo de análise teses, dissertações e artigos publicados em períodicos na área da educação. Com essa pesquisa, intencionava-se analisar as lacunas, permanecências e mudanças. Conclui-se apontando os aspectos comuns entre as pesquisas sobre o negro no Livro didático no período de 2003 a 2014 e sua relação com a Lei 10.639 de 9 de janeiro de 2003, que estabelece a obrigatoriedade do ensino da história e cultura afro-brasileira na educação básica.
\end{abstract}

Palavras-chave: Relações Étnico-raciais. Livro didático. Estado da Arte. Educação.

\begin{abstract}
This article presents the results of a systematic literature review of Brazilian's academic production regarding the textbooks and ethnic-racial relations. The research have analised thesis, dissertations and articles published in educational-wise journals. The intention of this article is to analyze the blanks, endurances and changes. The conclusion describes researches' common aspects about black people in textbooks. And also discuss it's
\end{abstract}

1 Pesquisa financiada pelo Conselho Nacional de Desenvolvimento Científico e Tecnológico (CNPQ), Coordenação de Aperfeiçoamento de Pessoal de Ensino Superior (CAPES), Fundação Araucária e Secretaria de Educação Continuada, Alfabetização, Diversidade e Inclusão do Ministério da Educação (SECADI/MEC).

* Universidade Federal Fluminense. Faculdade de Educação. Niterói, Rio de Janeiro, Brasil. E-mail: taniamuller@id.uff.br. ORCID: https://orcid.org/0000-0002-0838-7575 
relation with Law 10.639 / 2003 (that stablishes the teaching of AfricanBrazilian history and culture in basic education).

Keywords: Ethnic-Racial Relations. Textbooks. Systematic Review. Education.

\section{Introdução}

Este texto apresenta parte dos resultados finais referentes à categoria Livro Didático da pesquisa Educação e Relações Étnico-Raciais: o Estado da Arte. Esse estudo objetivava "sistematizar e analisar a produção acadêmica sobre educação e relações étnico-raciais entre 2003 e 2014 por meio da análise das teses e dissertações realizadas nos programas de pós-graduação stricto sensu em Educação e dos periódicos Qualis A e B na área da Educação" disponibilizadas nos bancos de dados da Capes.

Especificamente a categoria Livro Didático ${ }^{2}$ teve como objetivo mapear a produção acadêmica brasileira referente aos estudos sobre Livro Didático LD, Relações Étnico-raciais e Educação, expressas no corpus descrito acima. Trata-se de uma pesquisa qualitativa, na qual foram empregados análises e procedimentos de natureza quantitativa.

Para tanto, realizamos um levantamento bibliográfico das obras e sua seleção, a conjugação de informações, a organização e a classificação dos resultados com base nas técnicas definidas para os estudos de revisão do tipo "Estado da Arte" (Cf. MULLER, 2013; 2015). Entendemos que essa reunião e análise da produção acadêmica permitir-nos-á consolidar uma cartografia e um panorama da produção sobre o LD, apontando as suas contribuições, bem como as tendências, recorrências, mudanças, lacunas e emergências observadas por diferentes pesquisadoras/es, a partir da alteração do artigo 26A da Lei de Diretrizes e Bases da Educação - LDB -, com a promulgação da Lei n ${ }^{\circ}$ 10.639/2003.

Essa Lei determinou a implantação da História e Cultura Negra no currículo escolar e, consequentemente, no Livro Didático, na perspectiva de retificação, valorização e reconhecimento da participação de negras e negros na história brasileira e africana, através da ampliação dos referenciais textuais e iconográficos, e da exigência de uma nova abordagem sócio-histórica e cultural sobre a população negra. Outros documentos legais aprovados posteriormente

2 No decorrer deste texto priorizaremos o uso das siglas para Livro didático (LD) e Teses e Dissertações (TDs). 
configuram o conjunto de leis da Educação para as Relações Étnico-Raciais, que ratificam e ampliam os princípios da LDB na luta pela superação do racismo e do aporte epistemológico eurocêntrico.

A investigação permitiu evidenciar: o quantitativo; os contextos priorizados; a frequência regional, temporal e territorial de realização; o universo; os objetivos; principais abordagens metodológicas; autores e pesquisadores que vêm perquirindo ao longo dos anos a temática e uma síntese com a sistematização das implicações, conclusões e recomendações apontadas nos trabalhos. Consideramos que o LD é um importante objeto de estudo e que, ao ser eleito como matéria de investigação e de pauta de pesquisas acadêmicas, ratificam-nos como instrumentos pedagógicos ideológicos e de poder, "artefatos de currículo" (APPLE, 1995; SILVA, TEIXEIRA; PACÍFICO, 2013) que podem marcar e constituir a cultura material escolar (JULIA, 2001; SOUZA, 2007).

\section{As pesquisas sobre Livro Didático e Relações Étnico-raciais}

Foi nosso objetivo mapear, na área da Educação, a produção acadêmica (teses, dissertações e artigos) sobre LD publicadas e defendidas entre os anos de 2003 a 2014. Isso permitiu verificar o quantitativo da produção e se houve maior implicação da academia e de pesquisadores nos estudos sobre as relações étnico-raciais após a promulgação da Lei no 10.639/2003.

A pesquisa teve como diretriz os seguintes procedimentos metodológicos: coleta de dados; agrupamento de dados; revisão bibliográfica; mapeamento bibliográfico e dos dados; definição de categorias; análise descritiva dos dados; implicações, recomendações, mudanças, permanências e lacunas.

De acordo com Paulo Teixeira e Jorge Megid Neto (2006), a metodologia estado da arte pode ser classificada como pesquisa descritivo/explicativa com base na análise de documentos, definidas como:

[Estudos] descritivo-explicativos porque intencionam, num primeiro momento, identificar, descrever e explicar determinados fatos ou fenômenos - neste caso, a produção científica numa determinada área de pesquisa e, num segundo momento, estabelecer compreensão sobre o significado dessa produção no contexto da área de pesquisa. (TEIXEIRA; MEGID NETO, 2006, p. 267). 
Ao adotarmos essa metodologia tivemos como diretriz também o alerta evocado por Marli André et alii quando concluiu em seu estudo que houve "um excesso de discurso sobre o tema da formação docente e uma escassez de dados empíricos para referenciar práticas e políticas educacionais" (2005, p. 309). Dito de outra forma, o levantamento e a análise de dados quantitativos são fundamentais para um mapeamento da produção e a apreciação de práticas e políticas educativas.

Por isso, as pesquisas do tipo estado da arte representam também um esforço de ordenação e quantificação de certa produção de conhecimento que permite observar crescimento, ampliação, redução, ausências e entrecruzamentos de dados e sua utilização para produção de outras leituras. Os dados quantitativos fornecem índices que podem ser comparados, além de garantir uma uniformidade de apresentação e análise dos dados coletados, por utilizar tabelas, percentuais e gráficos.

Os agrupamentos das produções por nós analisadas foram embasados inicialmente nas seguintes categorias ${ }^{3}$ : Relações étnico-raciais (estudos que tem como foco a educação, o ensino e suas interfaces sobre a diversidade étnico-racial, políticas públicas, colonialidade relacionadas ao LD); Racismo (todos os temas trabalhados sobre racismo que tenham por objetivo a sua denúncia ou superação, bem como sobre raça/etnia no LD); Escravidão (estudos, avanços ou controvérsias sobre a Escravidão no LD), Negro (estudos sobre histórias, denúncias, revisões, avanços, visibilidade e invisibilidade do negro, africanos e afrodescendentes no LD e na Literatura); África (estudos que abordaram a África e sua representação, história e cultura); e Representação (estudos relacionados ou que tenham por referência investigar as ideias e conceitos explícitos ou implícitos e iconografias sobre o negro ou protagonismo do negro no LD).

A classificação das teses e dissertações (TDs) e dos artigos a constituir o conjunto da produção mapeada neste estudo foi realizada com base nos seguintes descritores: autor, orientador, instituição, área, ano de defesa ou publicação, grau de titulação acadêmica, formação do autor dos artigos e formação/campo de estudo do orientador e membros das bancas, palavras-chave, resumo, banca de defesa, suporte de publicação e região da produção, objetivo, metodologia, objeto de estudo, conclusões/recomendações, lacunas e emergências. Esses descritores são indexadores, parâmetros de registros de dados e classificação, já consagrados na pesquisa acadêmica, e muito utilizados nos trabalhos desenvolvidos pelos pesquisadores que trabalham com estudos de levantamento bibliográfico e estado da arte.

3 Tratam-se de categorias utilizadas em estudo de Tânia Müller, acatadas aqui devido a sua boa aplicabilidade e aos resultados obtidos (MÜLLER, 2015). 
A principal base de dados de referências para a busca das TDs e artigos foi o Banco de teses, dissertações e periódicos da CAPES, confrontada com outros, especificamente os bancos de dados das Instituições de Ensino Superior (IES) e Google Acadêmico. Após a exclusão de dezenas de itens, selecionamos especificamente aquelas produções que, com a leitura de título, palavras-chave e resumo, pudessem efetivamente compor o corpus desta investigação. Nossa concepção de LD está balizada em diferentes suportes teóricos que se coadunam (ROSEMBERG; BAZILLI; SILVA, 2003). Vale destacar, entretanto, nossa compreensão.

Historicamente os livros didáticos serviam, mormente, para auxiliar os professores que não possuíam a formação docente e também eram os principais instrumentos de disseminação do conteúdo e do método prescrito pelos setores dominantes. Porém, o livro didático tornou-se velozmente o material impresso mais difundido pelo país por atingir grande parte da população.

As obras didáticas caracterizam-se por tiragens elevadas, principal "artefato cultural" adquirido pelo Estado, o que significa que as editoras precisam constantemente fazer adaptações e ampliações textuais e iconográficas para obedecer aos programas oficiais, o que leva as empresas a adotarem diferentes fórmulas de produção e vendas, tornando-os acessíveis aos professores e alunos.

O livro didático histórica e socialmente foi construído como um importante instrumento político e lucrativo e representa até os dias atuais as permanências e modificações que se estabelecem dentro da sociedade, que se refletem na cultura material escolar. Porém, é preciso lembrar, como ensinou Paulo Freire (2011), que nada é escrito por acaso, tudo tem um cunho político ideológico, principalmente um livro didático, cujo trabalho é formar e disseminar conhecimentos.

\section{As pesquisas acadêmicas}

Nosso estudo iniciou-se pela formação de um quadro no qual pudéssemos agrupar as TDs sobre LD encontradas de acordo com os critérios apontados anteriormente. Com isso, podemos perceber a existência, no total de 29 TDs, sendo 25 dissertações e 4 teses.

Embora almejássemos que este quantitativo de TDs representasse a realidade dos dados e consideramos que os elementos trabalhados nesta pesquisa sejam significativos, reconhecemos que há, como em qualquer levantamento de dados, a possibilidade de algumas ausências, visto que nem sempre os estudos são disponibilizados nas plataformas de busca. De todo modo, a incerteza 
do quantitativo dos estudos sobre Relações Étnico-Raciais no LD é em nosso entendimento, bastante salutar, pois rompe com a ideia de que uma pesquisa do tipo "estado da arte" possa ser detentora da totalidade da produção sobre uma temática. Isso também nos permite concluir pela nossa impossibilidade de domínio de um campo de conhecimento, de recuperação de informações num longo espaço temporal e da fidedignidade da ciência, ou seja, revela nossos limites em ter, como disse Norma Ferreira, a "posse de tudo que se produz em todos os lugares em todos os tempos" (2002, p. 261).

Após o agrupamento de dados, classificamos as TDs por ordem alfabética das/os autoras/es. Cogitamos respeitar o marco temporal de catalogação das produções que compõem o universo da pesquisa, contudo, a organização por ordem alfabética facilita a busca na bibliografia e articulação de dados. Assim, pudemos, ao final, responder às perguntas: "onde", "quando", "como" e "quem" pesquisa sobre o tema num determinado espaço e tempo (FERREIRA, 2002; MÜLLER, 2015a).

Entendemos que as tabelas, quadros e gráficos constituem um banco de dados fundamental e de extrema significação para o nosso campo de conhecimento, visto portar informações que, relacionadas a outros estudos, podem dar margem para diferentes leituras e pesquisas, além de formar uma significativa cartografia da produção acadêmica para a área das relações étnico-raciais. Elas serviram apenas de objetos de leitura e indicativos para a compreensão do material produzido.

Seguimos organizando tabelas que espelhassem o universo da pesquisa, separando títulos e autores que trabalharam com a temática nas categorias já apresentadas. Observamos que a produção das TDs concentra-se nas universidades federais, sendo apenas cinco em IES privadas, particularmente nas Pontifícias Universidades Católicas (PUC).

Com base nos dados sobre regiões, foi possível chegar às seguintes constatações: no Sudeste incide o maior número de pesquisas e em diferentes universidades (52\%). Embora no Sul, especificamente na UFPR - Universidade Federal do Paraná, houve uma maior concentração de produção (24\%), seguido pelo Nordeste com $17 \%$ e a região Norte com apenas $7 \%$, havendo maior prevalência de produção sobre a temática em nível de mestrado. Se considerarmos os dados sobre ano de defesa pode-se notar um aumento da produção a partir dos anos 2009 (17\%), retornando em 2012 ao percentual de 2009. Uma das hipóteses que pode ser levantada é, como demostra Silva, Teixeira e Pacifico (2013), houve uma grande mudança no PNLD - Programa Nacional do Livro Didático a partir de 2007 e maiores pressões dos movimentos sociais, particularmente do Movimento Negro, e de intelectuais negros e especialistas para o implemento da Legislação (Lei $n^{\circ} 10.634 / 2003$ ), o que pode ter estimulado tanto os autores 
para a adequação do LD, em conformidade aos Editais, quanto do mercado editorial para seu cumprimento.

Quanto ao gênero dos autores/autoras das TDs, apuramos uma frequência de 13 pesquisas produzidas por mulheres $(44,8 \%)$ e 16 por autores do gênero masculino $(55,2 \%)$.

Em relação às categorias indexadoras, apuramos quatro estudos TDs sobre Racismo, sendo todas dissertações: Almeida, L. J. M. (2013); Santos; C (2013); Stelling (2006); Vazzoler (2006).

Com o termo África aferimos três estudos, sendo uma tese Boulos Júnior (2008) e duas dissertações: Oliveira Neto (2012); e Zago (2012).

Também localizamos três estudos com o termo Escravidão, com a diferença de serem uma dissertação e duas teses: Costa, W. (2006); Pina (2009); Silva Filho (2005); Roza (2014).

Com o termo Representação encontramos quatro pesquisas, sendo todas dissertações de mestrado: Farias (2009); Roza (2009); Silva Filho (2005); Souza, C. F. (2010).

A busca com o termo Negro apresentou o número de seis estudos, sendo todas dissertações. São elas: Branco (2005); Carvalho, A. A. (2006); Carvalho, A. L. (2012); Costa, C. (2004); Oliveira, M. S. (2009); Russo (2012).

Já aquelas com foco em Relações Étnico-Raciais encontramos nove dissertações: Almeida, N. (2013); Junia (2010); Mathias (2011); Nascimento (2009); Pacifico (2011); Santos, K. (2009); Santos, R. (2013); Santos, W. (2012); Silva, R. (2014).

Pretendíamos organizar as palavras-chaves seguindo as mesmas categorias de agrupamento dos títulos (Racismo; Relações étnico-raciais; África; Escravidão; Negro e Representação), com isso, poderíamos analisar as áreas temáticas de maior concentração ao mesmo tempo em que poderiam servir de guia para novos trabalhos. No entanto, percebemos que se trata de termos muitos díspares. As categorias previamente selecionadas, ao nosso ver, não dão conta para contemplar tal mosaico.

Em relação à periodicidade de publicação das TDs constata-se a existência de: uma em 2004 (COSTA, C., 2004); duas em 2005 (BRANCO, 2005; SILVA FILHO, 2005); quatro em 2006 (CARVALHO, A. A., 2006; COSTA, W., 2006; STELLING, 2006; VAZZOLER, 2006); uma em 2008 (BOULOS JÚNIOR, 2008); cinco em 2009 (FARIAS, 2009; NASCIMENTO, 2009 PINA, 2009; OLIVEIRA, 2009; ROZA, L., 2009); duas em 2010 (JUNIA, 2010; SOUZA, C., 2010); três em 2011 (MATHIAS, 2011; PACIFICO, 2011; SANTOS, K., 2011); cinco em 2012 (CARVALHO, A. L., 2012; OLIVEIRA NETO, 2012; RUSSO, 2012; SANTOS, W., 2012; ZAGO, 2012); três em 2013 (ALMEIDA, 
L., 2013; SANTOS, C., 2013; SANTOS, R., 2013); ALMEIDA, N., 2014; ROZA, L., 2014; SILVA, R., 2014).

As seguintes IEs - Instituições de Ensino Superior - foram responsáveis pela produção acadêmica analisada: Pontifícia Universidade Católica de São Paulo - PUC/SP (ZAGO, 2012; SILVA, R., 2014; BOULOS JÚNIOR, 2010); Pontifícia Universidade Católica de Minas Gerais - PUC/MG (OLIVEIRA, 2009); Pontifícia Universidade Católica do Paraná - PUC/PR (ALMEIDA, N. 2014) Universidade de Sorocaba - UNISO (SOUZA, 2010); Universidade do Estado da Bahia - UEB (CARVALHO, A. L., 2012); Universidade do Estado do Rio de Janeiro - UERJ RUSSO, 2012); Universidade Estadual de Campinas - Unicamp (PINA, 2009); Universidade Federal de Alagoas - UFAL (SANTOS, K, 2011); Universidade Federal de Feira de Santana - UFFS (ALMEIDA, 2013); Universidade Federal de Minas Gerais - UFMG (SILVA FILHO, 2005, ROZA, L., 2009; JUNIA, 2010; ROZA, L., 2014); Universidade Federal de Pernambuco - UFPE (BRANCO, 2005); Universidade Federal de Santa Catarina - UFSC (CARVALHO, A. A., 2006); Universidade Federal do Estado do Rio de Janeiro - UNIRIO (SANTOS, C., 2013); Universidade Federal do Mato Grosso - UFMT (FARIAS, 2009, COSTA, C., 2004); Universidade Federal do Paraná - UFPR (PACIFICO, 2011; OLIVEIRA NETO, 2012; NASCIMENTO, 2009; MATHIAS, 2011; SANTOS, W., 2012);Universidade Federal do Rio de Janeiro - UFRJ (COSTA, W., 2006); Universidade Federal Fluminense - UFF (VAZZOLER, 2006; STELLING, 2007); Universidade Federal do Maranhão - UFMA (SANTOS, R., 2013).

As principais instituições orientadoras de estudos sobre LD foram a UFPR com cinco; a UFMG com quatro; em seguida a PUC/SP com três; a UFMT e a UFF com duas cada. Com apenas uma pesquisa foram as seguintes IES: UEFS, PUC/PR; UERJ; UNIRIO; UFAL; UFMA; UNISO; UFSC; UEBA; PUC/MG; UFRJ; UFPE, e Unicamp. O principal orientador de LD foi o professor Doutor Paulo Vinicius Baptista da Silva da UFPR, com cinco dissertações. As demais foram orientadas por diferentes pesquisadores, uma cada.

As áreas disciplinares privilegiadas para estudo dos LDs nas TDs resultam em: 14 em História (BOULOS JÚNIOR, 2010; BRANCO, 2005; CARVALHO, A. A. 2006; COSTA, W., 2006; FARIAS, 2009; OLIVEIRA, 2009; PINA, 2009; ROZA, L., 2014; ROZA, L., 2009; RUSSO, 2012; SILVA FILHO, 2005; SOUZA, C., 2010; SILVA, R., 2014; SANTOS, K. 2012); cinco em Língua Portuguesa (CARVALHO, A. L., 2012; COSTA, C., 2004; JUNIA, 2010; PACIFICO, 2011; SANTOS, R., 2013); quatro em Geografia (SANTOS, C., 2013; SANTOS, W., 2012; VAZZOLER, 2006 e ZAGO, 2012); duas em Artes (OLIVEIRA NETO, 2005; SILVA, R., 2014); uma em Biologia (STELLING, 2007); uma em Ciências 
(MATHIAS, 2011); uma em Ensino Religioso (NASCIMENTO, 2009); uma em Educação Física (PACIFICO, 2011).

Observa-se com isso a grande concentração na área de história, talvez por conta da Lei que orienta a inclusão do estudo da história e cultura negra no currículo. Cabe ressaltar que tanto Tânia Pacifico (2011) como Regina Silva (2014) abordaram duas áreas em suas pesquisas: Língua Portuguesa e Educação Física, e História e Arte, respectivamente. Uma pesquisa teve como área de estudo o LD de História da Educação com a intenção de análise da Legislação e Políticas educacionais (ALMEIDA, N., 2014). Outra teve como foco os Editais do PNLD e os Guias dos LDs elaborados pelo MEC (ALMEIDA, L. 2013).

Três trabalhos complementaram suas investigações incluindo entrevistas e questionários aplicados a professores e alunos na perspectiva de revelar seus modos de compreensão e ressignificação de textos e imagens (COSTA, C., 2004; VAZZOLER, 2006; SOUZA, C., 2010).

LDs de todos os segmentos da Educação Básica foram adotados como objeto de estudo, apurando-se o seguinte resultado: ensino fundamental I, nove TDs (BOULOS JÚNIOR, 2010; COSTA, W., 2006; FARIAS, 2009; JUNIA, 2010; OLIVEIRA, 2009; SANTOS, W., 2012; SANTOS, R., 2013; SILVA, R. 2014; VAZZOLER, 2006); Ensino fundamental II, 14 TDs (BRANCO, 2005; CARVALHO, A. A., 2006; CARVALHO, A. L., 2012; COSTA, C., 2004; MATHIAS, 2011; NASCIMENTO, 2009; PACIFICO, 2011; ROZA, L., 2014; ROZA, L., 2009; RUSSO, 2012; SANTOS, C., 2013; SILVA FILHO, 2005; SOUZA, C., 2010 e SANTOS, K., 2012 - esta na modalidade de EJA); e quatro em Ensino Médio (OLIVEIRA NETO, 2005; PINA, 2009; STELLING, 2007; ZAGO, 2012).

As pesquisas concentraram-se em analisar a partir da Lei $\mathrm{n}^{\circ} 10.639 / 2003$ as mudanças e permanências nos textos e imagens referentes à história do negro e/ou da África em LD. As principais metodologias adotadas foram a Hermenêutica de Profundidade (THOMPSON, 2007; 2008; a análise sócio-histórica, a análise discursiva e a interpretação/reinterpretação de textos verbais e não verbais para apropriar-se do sentido e ideologias do texto); Análise do Discurso (PECHEUX, 2010; descoberta das pistas que podem levar à interpretação dos sentidos, a descoberta das marcas estruturais e ideológicas dos textos) e a Análise de Conteúdo (BARDIN, 2009, objetiva a descoberta das relações existentes entre o conteúdo do discurso e os aspectos exteriores), tendo como referência o que demanda o PNLD e as orientações normativas. Apenas uma adotou os estudos pós-coloniais (SANTOS; MENEZES, 2010) para compreensão e leitura dos LDs, o que podemos aferir como uma questão emergente.

Apesar de apontarem mudanças nos LDs analisados, os autores concordam com a permanência de representações estereotipadas da população negra, quando 
destacam o uso de iconografias relacionadas a miséria, violência, escravidão, reduzidas muitas vezes à folclorização.

Constatamos onze artigos sobre o Livro Didático, dos quais quatro foram publicados em revistas com Qualis A1 (ROSEMBERG; BAZILLI; SILVA, 2003; ARAÚJO; MAESO, 2013; SANTOS, W. O., 2013; SILVA;,TEIXEIRA; PACIFICO, 2013); dois com B1 (MÜLLER, 2013; PASSOS; CHAMPLIAU, 2010), quatro com B3 (SILVA, P. V., 2006; LEITE; BARDUNI FILHO, 2013; LIMA; SOUSA, 2014; SANTOS, W. O., 2014), e apenas um com B4 (SANTOS, U. G., 2010). Trata-se de textos resultantes de pesquisas realizadas pelos autores sobre a temática, que apresentam grandes contribuições para compreensão dos procedimentos metodológicos e do objeto de estudo e seu contexto sócio-histórico, avanços e permanências.

As revistas que publicaram os 11 artigos foram quantificadas tomando como referência suas classificações em Qualis CAPES. Com Qualis A1 foram as revistas: "Ciência \& Educação (Bauru)" e "Educar em Revista", com um artigo cada; e "Educação e Pesquisa", com dois artigos. Com B1 foi a revista "Revista Teias", com dois artigos. Com B3 foram as revistas: "Poiésis-Unisul", "Dialogia", "Revista Intermeio" e "Revista Instrumento" com um artigo cada. Com Qualis B4 foi a revista "Revista África e Africanidades", com um artigo.

A análise da formação dos autores permitiu observar que se trata de pesquisadores da área com formação sólida e consolidada sobre as temáticas abordadas, o que nos possibilita considerar a relevância dos seus escritos. No entanto, podemos observar com esses dados que ainda se trata de um tema de pouca referência e impacto.

Neste momento, faz-se preciso resgatar os pontos de entraves para a realização desta pesquisa, que podem vir a contribuir como subsídio relevante para outros pesquisadores e uma maior atenção da academia na publicização de seus trabalhos.

Sabemos que o processo de entrega das TDs para envio à Capes é de responsabilidade do autor. Portanto, alguns dados aqui observados podem ter sido objeto de críticas e alvo de destaque nas observações e comentários dos componentes das bancas avaliadoras no momento da defesa pública da pesquisa. No entanto, observamos que nem sempre foram atendidas pelos mestrandos ou doutorandos no processo de postagem no site da Capes ou entrega do material digitalizado ao Programa de Pós-graduação.

Alguns elementos que destacamos podem ser definidos como recorrentes de formas e se referem ao cumprimento das normas gerais de apresentação e publicação de Teses e Dissertações de acordo com as orientações da Associação Brasileira de Normas Técnicas - ABNT -, tais como: ausência de numeração das páginas; páginas repetidas no corpo do texto; descumprimento das normas 
bibliográficas, de citação e referências no texto, de notas de rodapé; uso de modelos diversos de citação e referências no mesmo texto; ausência de página de assinatura e composição de banca, de folha de rosto, de resumo, tanto em língua portuguesa quanto em língua estrangeira, de lista de quadros e tabelas e de palavras-chave; erros ou omissão de bibliografias citadas no texto nas referências; citações e paráfrases sem referências; além de erros gramaticais e ortográficos grosseiros e textos incompletos.

Constatamos que há pouca atenção na observação e exigências quanto aos resumos apresentadas nas TDs, o que pode dar a entender que se trata de item de pouca importância acadêmica. De acordo com Antônio Severino (1994), o resumo é o marco inicial de leitura dos pesquisadores na seleção de referenciais bibliográficos e, por isso, ele deve apontar, de forma sucinta, clara e precisa, todos os dados da pesquisa, quais sejam: objetivo, justificativa, procedimentos metodológicos, referenciais teóricos, universo da pesquisa e conclusões. A sua insuficiência pode constituir um grande entrave para pesquisas do tipo "estado da arte" e na desimplicação e desqualificação durante a efetuação de outros procedimentos tais como a busca e leitura do documento original.

Como descrevemos anteriormente, os estudos apontaram que o livro didático foi tomado como objeto de pesquisa por ser um instrumento de alta relevância no contexto da educação brasileira e para o mercado editorial. Contudo, percebemos algumas lacunas que ainda devem ser mais investigados, tais como: a análise dos próprios livros e seus conteúdos; a concepção, produção e difusão; os discursos textuais, análise de discurso, de conteúdo e a relação com as iconografias; as atuações do Movimento negro e seus diálogos, embates e divergências com o Estado brasileiro e a sociedade civil e algumas de suas conquistas ao longo da República; estudos da iconografia escolar relativa à África, aos africanos e seus descendentes e sua relação com o texto e o projeto gráfico; o uso do LD pelo professor e aluno, incluindo processo de escolha, análise, e leituras para seleção; o autor do LD, destacando a formação, indicação e processo de elaboração e seleção de conteúdo do LD; as políticas do LD, abarcando o processo de avaliação e aprovação; e o mercado editorial (escolha do autor, material, distribuição, divulgação, custos, adequação aos editais e público); estudos de natureza histórica sobre livros e edições; e preocupação com a qualidade do LD, tanto no que se refere ao aspecto físico como textual; depoimentos de alguns de seus autores e ilustradores; perspectivas do cotidiano dos escravizados pouco trabalhados nos LDs, reconhecimento do papel do ilustrador como agente influenciador e, por fim, como o poder ideológico do LD e seu discurso hegemônico, eurocêntrico e colonialista interfere na compreensão da história e cultura negra e de África por alunos e professores. 
Esta análise permite-nos dizer que os livros didáticos suscitam interesse entre os pesquisadores, e constatamos a sua expansão como campo de investigação se compararmos aos dados obtidos em pesquisas anteriores ${ }^{4}$.

No nosso universo de estudo os autores em geral ressaltam, quando falam de África, que permanecem aspectos recorrentes: fome, doenças, guerras e conflitos políticos assim como a precariedade de vida das populações permaneceram. As temáticas recursivas continuam sendo explicadas pelo período da dominação imperialista e pelo olhar do colonizador. Pouco se enfatiza o legado cultural da África e suas populações ao longo dos conteúdos apresentados.

Os autores observaram ainda que os livros apresentaram uma utilização mais variada dos recursos iconográficos, assim como uma ampliação do conteúdo textual relacionado à temática após a Lei $n^{\circ} 10.639 / 2003$, talvez por exigência dos editais do PNLD, mas nem sempre se estabelece uma relação entre texto, imagem e legenda.

O principal tema emergente encontrado trata-se do conceito Colonialidade do Poder, que parte da premissa de compreensão do lugar que ocupamos nas relações de poder enquanto povo (des)colonizado. Essa concepção, que tem como base os estudos pós-coloniais, desenvolvidos em sua maioria por intelectuais latino-americanos, ao analisar o mundo a partir de suas margens, percebe o poder sob uma outra perspectiva epistemológica, de uma ecologia de saberes, conforme definição de Boaventura de Souza Santos, cujo "reconhecimento da diversidade epistemológica do mundo, o reconhecimento da existência de uma pluralidade de formas de conhecimento além do conhecimento científico" (SANTOS; MENEZES, 2009 , p. 54) induza a renúncia de qualquer epistemologia geral, para que cada grupo humano tenha a possibilidade de enxergar o mundo com seu próprio "olhar".

A permanência de estereótipos, preconceitos e silenciamento da história, cultura e personagens negros nos LDs estabelece um pressuposto que Rosemberg, Bazilli e Silva (2003) descrevem muito bem: o desafio mais crítico para aqueles que lutam contra o racismo no Brasil está justamente em convencer a opinião pública do caráter sistemático e não casual dessas desigualdades. Combater o racismo não significa lutar contra indivíduos, mas se opor às práticas e ideologias.

Como recomendações para avanço do conhecimento, concordamos com os autores que consideram relevante o intenso investimento na formação inicial e

4 A pesquisa realizada por Rosemberg, Bazilli e Silva (2003) sobre teses e dissertações defendidas em programas de pós-graduação filiados à Associação Nacional de Pós-Graduação e Pesquisa em Educação (ANPED), no período 1981-1998, constatou a existência de 114 títulos sobre o tema do livro didático, porém apenas quatro estavam relacionados ao racismo (estereótipo, preconceito ou discriminação). 
continuada de professores, de modo que possam aportar ao seu fazer pedagógico a educação das relações étnico-raciais, com vistas a possibilitar a ressignificação e desconstrução daqueles conceitos e conteúdos veiculados pelo LD de forma preconceituosa e discriminatória, bem como nos procedimentos de escolha do LD mais criteriosos.

\section{Algumas considerações finais}

Podemos afirmar, a partir da leitura das produções acadêmicas, que a alteração do artigo 26A da LDB/1988, após promulgação da Lei n ${ }^{\circ} 10.639 / 2003$, trouxe algumas mudanças de caráter quantitativo nos conteúdos escolares e no LD sobre a inclusão da história e cultura negra e da África. Porém, essas transformações ainda não podem ser consideradas significativas e impactantes na cultura escolar, pois podem ser compreendidas apenas para atendimento e adequação à demanda legal, ou seja, ao PNLD e o cumprimento legal.

Os autores, assim como nós, acreditam que maiores estudos e análises sobre o negro no LD são necessários, uma vez que o LD é instrumento recorrente de uso e trabalho docente e parte da cultura material escolar, que ainda estão eivados de discriminação, preconceito e ideologias com as quais o racismo opera através das relações culturais e sociais. A exposição e crítica do material pode permitir que docentes e a escola se tornem mais competentes para perceberem e denunciarem com propriedade o racismo no cotidiano escolar.

Outro aspecto dos LDs observados diz respeito à quantidade de imagens sobre a escravidão e as condições de vida dos sujeitos escravizados, muitas vezes usadas para ilustrar e não para acrescentar informação, conhecimento e crítica. E lembramos que mesmo obedecendo às normativas, os manuais didáticos sofrem interferências mercadológicas para serem escolhidos pelas escolas públicas.

Também podemos destacar uma questão relacionada à escravidão no Brasil. A ênfase dada nos livros é tradicionalmente voltada para os senhores de engenho, a casa-grande, as relações de produção, deixando de apresentar as lutas e resistências dos negros, seus conhecimentos, tecnologias, histórias e participação na construção e formação da nação brasileira.

Nota-se que as mudanças no LD ocorreram, entretanto, estão longe do ideal, pois de acordo com os estudos, aconteceram de forma parcial. Assim, se faz necessário prementes modificações substanciais na organização e inclusão de conteúdos e imagens desmistificadoras de estereótipos, bem como na naturalização de personagens de várias etnias num lugar de miséria ou bestializados, ou 
ainda sua ausência ou silenciamento em outros espaços tais como nas ciências, nas diferentes profissões, no domínio das tecnologias, na literatura, na filosofia, na cultura, no cinema, na televisão, e nas diferentes artes.

Constatamos que, em quase sua totalidade, os estudos apontam pela necessidade de um maior investimento na formação de professores, de forma que os levem a se comprometerem efetivamente com uma educação antirracista, e que essa formação deverá propiciar suporte teórico que lhes permitam: escolher de modo mais criterioso os livros didáticos e outros textos auxiliares na aquisição dos conhecimentos científicos; trabalhar com a questão das relações étnico-raciais no espaço escolar de modo mais permanente; minorar e denunciar situações e eventos explícitos de preconceito, discriminação e violência instalados nas escolas; aumentar o índice de permanência e sucesso escolar da população negra; trabalhar na construção da autoestima e da identidade étnico-racial dos alunos.

Após este agrupamento e a leitura dos trabalhos podemos afirmar que o principal foco das pesquisas estaria em denunciar o racismo e propor uma educação antirracista.

No entanto, não podemos nos abster de anunciar que detectamos a ausência de propostas de usos diversificados do LD no cotidiano da sala de aula; explicitação do saber docente revelado durante o uso do $\mathrm{LD}$; silêncio sobre pesquisas de formação docente para uso do LD de forma crítica, o LD em interação com outras tecnologias e confrontação com outros veículos de informação; saber escolar e cultura material escolar; análises do envolvimento e do comprometimento dos professores nas escolhas dos livros didáticos antes da solicitação ao MEC/ $\mathrm{FNDE}^{5}$. Porém, para além de formar docentes para uma melhor apropriação dos conteúdos e práticas pedagógicas, faz-se necessário mudar os raciocínios e as posturas presentes na cultura escolar com vistas à superação do racismo. Entendemos que junto a isso, e com a adoção de um currículo multiculturalista e intercultural poderá propiciar uma efetiva intervenção nos cotidianos da escola causados pela incompreensão e desrespeito às diferenças étnico-raciais dos sujeitos.

5 FNDE - Fundo Nacional de Desenvolvimento da Educação - é o órgão responsável pela aquisição, e distribuição do LD às escolas. 


\section{REFERÊNCIAS}

ANDRÉ, M. E. D. A. Etnografia da prática escolar. Campinas, SP: Papirus, 2005.

APPLE, M. Cultura e comércio do livro didático. In: APPLE, M. Trabalho docente e textos. Porto Alegre: Artes Médicas, 1995.

BARDIN, L. Análise de conteúdo. Lisboa, Portugal: Edições 70, LDA, 2009.

BITTENCOURT, C. Livro didático e saber escolar (1810-1910). Belo Horizonte: Autêntica Editora, 2008.

COELHO, W. de N. B.; SILVA, R. M. de N. B. Relações Raciais e Educação: o estado da arte. Revista Teias, v. 14, n. 31, p. 121-146, maio/ago. 2013.

FERREIRA, N. S. de A. As pesquisas denominadas "Estado da Arte". Educação \& Sociedade, v. 23, n. 79, p. 261, 2002.

GASPARELlO, A. M. Construtores de identidade: a pedagogia da nação nos livros didáticos da escola brasileira. São Paulo: Iglu, 2004.

JULIA, D. A cultura escolar como objeto histórico. Revista Brasileira de História da Educação, Campinas, n. 1, p. 9-44, 2001.

MÜLLER, T. M. P. O Negro no Livro Didático: o que nos contam as imagens? In: BARRETO, M. A. et al. Africanidade(s) e Afrodescendência(s): perspectivas para a formação de professores. Vitória: EDUFES, 2013. p. 57-70.

MÜLLER, T. M. P. As pesquisas sobre o "estado do conhecimento" em relações étnico-raciais. Revista do Instituto de Estudos Brasileiros, v. 62, p. 164-183, 2015a.

MÜLLER, T. M. P. Estudos sobre imagem do negro no livro didático. In: MÜLLER, T. M. P.; COELHO, W. Relações étnico-raciais, formação de professores e currículo. São Paulo: Ed. Livraria da Física, 2015 b.

PÊCHEUX, M. Análise Automática do Discurso (AAD-1969). In: GADET, F.; HAK, T. (Org.). Por uma Análise Automática do Discurso: uma introdução à obra de Michel Pêcheux. Trad. de Eni P. Orlandi. Campinas: Unicamp, 2010. p. 59-158.

SANTOS, B. de S.; MENESES, M. P. (Org.). Epistemologias do Sul. Coimbra: Edições Almedina, 2009.

SEVERINO, A. J. Metodologia do Trabalho Científico. São Paulo: Cortez, 1994.

SILVA, A. C. A discriminação do negro no livro didático. Salvador: EdUFBA, 2005.

SILVA, P. V. B. da. Racismo em livros didáticos. Belo Horizonte: Autêntica, 2008.

SOUZA, R. F. de. História da cultura material escolar: um balanço inicial. In: BENCOSTA, M. L. (Org.). Culturas escolares, saberes e práticas educativas: itinerários históricos. São Paulo: Cortez, 2007. 
TEIXEIRA, P. M. M.; MEGID NETO, J. Investigando a pesquisa educacional. Um estudo enfocando de dissertações e teses sobre o ensino de biologia no Brasil. Investigações em Ensino de Ciências, v.11(2), p. 261-282, 2006.

THOMPSON, J. B. Ideologia e Cultura Moderna: teoria social crítica na era dos meios de comunicação de massa. Petrópolis: Vozes, 2007.

THOMPSON, J. B. Mídia e a modernidade. Petrópolis: Vozes, 2008.

\section{Teses e Dissertações analisadas}

ALMEIDA, L. J. M. de. “Velhos problemas, novas questões”: uma análise dos discursos raciais na política nacional do livro didático. 2013. Dissertação (Mestrado em Educação) - Universidade Estadual de Feira de Santana, 2013.

ALMEIDA, N. P. A construção da invisibilidade e da exclusão da população negra nas práticas e políticas educacionais no Brasil. 2014. Tese (Doutorado em Educação) - Pontifícia Universidade Católica do Paraná, 2014.

BOULOS JÚNIOR, A. Imagens da África, dos africanos e seus descendentes em coleções de didáticos de história aprovadas no PNLD de 2004. 2008. Tese (Doutorado em Educação) - Pontifícia Universidade Católica de São Paulo, 2008.

BRANCO, R. C. O negro no livro didático de História do Brasil para o Ensino Fundamental II da rede pública estadual de ensino, no Recife. 2005. Dissertação (Mestrado em Educação) - Universidade Federal de Pernambuco, 2005.

CARVALHO, A. L. S. de. A ressignificação da história do negro nos livros didáticos de história. 2012. Dissertação (Mestrado em Educação) - Universidade do Estado da Bahia, 2012.

CARVAlHO, A. A. de M. C. de. As imagens dos negros em livros didáticos de História. 2006. Dissertação (Mestrado em Educação) - Universidade Federal de Santa Catarina, 2006.

COSTA, C. S. da. O negro no livro didático de Língua Portuguesa: imagens e percepções de alunos e professores. 2004. Dissertação (Mestrado em Educação) - Universidade Federal do Mato Grosso, 2004.

COSTA, W. da. As imagens da escravidão nos livros de história do ensino fundamental: representações e identidades. 2006. Dissertação (Mestrado em Educação) - Universidade Federal do Rio de Janeiro, 2006.

FARIAS, M. do N. Representações dos negros nos livros escolares utilizados em Mato Grosso na Primeira República. 2009. Dissertação (Mestrado em Educação) - Universidade Federal do Mato Grosso, 2009.

JUNIA, E. R. da S. Discursos sobre relações raciais em livros didáticos de português para as séries iniciais do ensino fundamental. 2010. Dissertação (Mestrado em Educação) - Universidade Federal de Minas Gerais, 2010. 
MATHIAS, A. L. Relações raciais em livros didáticos de ciências. 2011. Dissertação (Mestrado em Educação) - Universidade Federal do Paraná, 2011.

NASCIMENTO, S. L. do. Relações raciais em livros didáticos de ensino religioso do ensino fundamental. 2009. Dissertação (Mestrado em Educação) - Universidade Federal do Paraná, 2009.

OLIVEIRA NETO, M. G. de. Arte e silêncio: a arte africana e afro-brasileira nas diretrizes curriculares estaduais e no livro didático público de arte do Paraná. 2012. Dissertação (Mestrado em Educação) - Universidade Federal do Paraná, 2012.

OLIVEIRA, M. S. A representação dos negros em livros didáticos de história: mudanças e permanências após a promulgação da Lei 10.639/03. 2009. Dissertação (Mestrado em Educação) - Pontifícia Universidade Católica de Minas Gerais, 2009.

PACIFICO, T. M. Relações raciais no livro didático público do Paraná. 2011. Dissertação (Mestrado em Educação) - Universidade Federal do Paraná, Curitiba, 2011.

PINA, M. C. D. A escravidão no livro didático de história do Brasil: três autores exemplares (1890-1930). 2009. Tese (Doutorado em Educação) - Universidade Estadual de Campinas, 2009.

ROZA, L. M. A história afro-brasileira pós-abolição em livros didáticos. 2014. Tese (Doutorado em Educação) - Universidade Federal de Minas Gerais, 2014.

ROZA, L. M. Entre sons e silêncios: apropriações da música no livro didático no ensino de história afro-brasileira. 2009. Dissertação (Mestrado em Educação) - Universidade Federal de Minas Gerais, 2009.

RUSSO, R. F. M. Contribuições para o estudo da imagem dos negros: avanços e permanências das imagens utilizadas nos livros didáticos de história, pós-implementação da Lei 10639/03. 2012. Dissertação (Mestrado em Educação) - Universidade do Estado do Rio de Janeiro, 2012.

SANTOS, C. A. C. dos. Sob a névoa do norte: reflexões sobre colonialidade, "raça" e livros didáticos de Geografia do ensino fundamental. 2013. Dissertação (Mestrado em Educação) - Universidade Federal do Estado do Rio de Janeiro, 2013.

SANTOS, K. de O. As relações étnico-raciais no livro didático da educação de jovens e adultos: implicações curriculares para uma sociedade multicultural. 2011. Dissertação (Mestrado em Educação) - Universidade Federal de Alagoas, 2011.

SANTOS, R. C. P. dos. A educação das relações etnicorraciais em livros didáticos de Lingua Portuguesa no ensino médio. 2013. Dissertação (Mestrado em Educação) - Universidade Federal do Maranhão, 2013.

SANTOS, W. O. dos. Relações raciais, Programa Nacional do Livro Didático (PNLD) e livros didáticos de Geografia. 2012. Dissertação (Mestrado em Educação) - Universidade Federal do Paraná, 2012. 
SILVA FILHO, J. B. da. Os discursos verbais e iconográficos sobre os negros em livros didáticos de história. 2005. Dissertação (Mestrado em Educação) - Universidade Federal de Minas Gerais, 2005.

SILVA, R. M. da. Educação das relações étnico-raciais nos cadernos didáticos "Formadores do Saber" (2011 - 2012): análise da experiência da rede Municipal de Santo André. 2014. Dissertação (Mestrado em Educação) - Pontifícia Universidade de São Paulo, 2014.

SOUZA, C. de F. de. A representação étnico-racial do segmento social negro: livros didáticos de História. 2010. Dissertação (Mestrado em Educação) - Universidade de Sorocaba, 2010.

STELLING, L. F. P. "Raças humanas” e raças biológicas em livros didáticos de Biologia de ensino médio. 2007. Dissertação (Mestrado em Educação) - Universidade Federal Fluminense, 2007.

VAZZOLER, L. dos S. A questão racial no ensino de Geografia. 2006. Dissertação (Mestrado em Educação) - Universidade Federal Fluminense, 2006.

ZAGO, A. de B. A representação do Continente Africano nos livros didáticos de geografia do ensino médio. 2012. Dissertação (Mestrado em Educação) - Pontifícia Universidade Católica de São Paulo, 2012.

\section{Artigos analisados}

ARAÚJO, M.; MAESO, S. R. A presença ausente do racial: discursos políticos e pedagógicos sobre História, "Portugal" e (pós-) colonialismo. Educar em Revista, Curitiba, n. 47, jan./mar. 2013.

LEITE, A. da S.; BARDUNI FILHO, J. Algumas considerações sobre a educação antirracista nas séries iniciais do ensino fundamental. Revista Instrumento, Minas Gerais, v. 15, n. $1,2013$.

LIMA, D. M.; SOUSA, C. A. Como os currículos escolares podem contribuir para uma política antirracista nas escolas. Dialogia, São Paulo, n. 20, p. 85-98, jul./dez. 2014.

MÜLLER, T. M. P. A história que não é contada: narrativas docentes sobre a escolha do livro didático e a Lei 10.639/03. Revista Teias, v. 14, n. 34, 2013.

PASSOS, M. C.; CHAMPLIAU, R. B. S. O colonizado vai à escola do colonizador: reflexões sobre as imagens em um livro didático da escola colonial francesa na Argélia. Revista Teias, v. 11, n. 21, 2010.

ROSEMBERG, F.; BAZILLI, C.; SILVA, P. V. Baptista da. Racismo em livros didáticos brasileiros e seu combate: uma revisão da literatura. Educação e Pesquisa, v. 29, n. 1, São Paulo jan./jun., 2003.

SANTOS, U. G. Livros didáticos: contribuição para aplicação no ensino de história e cultura afro-brasileira e indígena em instituições de ensino públicos e particulares. Revista Africa e Africanidades, Rio de Janeiro, ano 3, n. 10, ago. 2010. 
SANTOS, W. O. dos. Espaços de negros e brancos em livros didáticos de Geografia do estado do Paraná. Ciência e Educação (Bauru), v. 19, n. 4 Bauru, 2013.

SANTOS, W. O. A Lei 10.639/03 e os livros didáticos de Geografia. Poiesis - Unisul, v. 8, n. 13, 2014.

SILVA, P. V. Racismo discursivo e avaliações do Programa Nacional de Livros Didáticos. Revista Intermeio, Campo Grande, MS, v. 12, n. 24, p. 6-29, jul.-dez. 2006.

SILVA, P. V. B.; TEIXEIRA, R.; PACIFICO, T. M. Políticas de promoção de igualdade racial e programas de distribuição de livros didáticos. Educação e Pesquisa, São Paulo, v. 39, n. 1, jan./mar. 2013.

Texto recebido em 29 de dezembro de 2017.

Texto aprovado em 30 de dezembro de 2017. 
